\title{
МЕЧЕНИЕ ЛИНОЛЕВОЙ КИСЛОТЫ УГЛЕРОДОМ-14 И -13 ДЛЯ ПРОВЕДЕНИЯ ДИАГНОСТИЧЕСКИХ ДЫХАТЕЛЬНЫХ ТЕСТОВ ЗАБОЛЕВАНИЙ ГЕПАТОБИЛИАРНОЙ СИСТЕМЫ
}

\author{
Я.Я. Тыньо, Г. В. Морозова, Ю. К. Бирюкова, Д.А. Сивохин, А. В. Белякова, \\ Н. В. Позднякова, Е. Ю. Григорьева, Е. С. Мутных, А. Б. Шевелев
}

ЯРОСЛАВ ЯРОСЛАВОВИЧ ТЫНЬО - к.б.н., доцент Российского государственного университета физической культуры, спорта, молодежи и туризма.E-mail: yytynio@mail.ru.

ГАЛИНА ВАДИМОВНА МОРОЗОВА - аспирант Московской государственной академии ветеринарной медицины и биотехнологии - МВА имени К.И. Скрябина.E-mail: 5448372@mail.ru.

ЮЛИЯ КОНСТАНТИНОВНА БИРЮКОВА - к.б.н., старший научный сотрудник Института биохимической физики имени Н.М. Эмануэля РАН, федерального научного иеентра исследований и разработки иммунологических препаратов имени М. П. Чумакова РAH. E-mail: biriukova-ula@mail.ru.

ДМИТРИЙ АЛЕКСЕЕВИЧ СИВОХИН - студент Первого Московского государственного медиичнского университета им. И.М. Сеченова (Сеченовский Университет).E-mail: dr.sivokhin@gmail.com.

АЛЛА ВЛАДИМИРОВНА БЕЛЯКОВА - к.б.н., научный сотрудник Института биохимической физики имени Н.М. Эмануэля РАН, федерального научного иентра исследований и разработки иммунологических препаратов имени М. П. Чумакова РАH. E-mail: allusya_uzтu@mail.ru.

НАТАЛЬЯ ВЛАДИМИРОВНА ПОЗДНЯКОВА - к.б.н., старший научный сотрудник Начионального медищинского исследовательского иееттра онкологии имени Н. Н. Блохина. E-mail: natpo2002@mail.ru.

ЕЛЕНА ЮРЬЕВНА ГРИГОРЬЕВА - д.б.н., заведующая отделением Наџионального медицинского исследовательского цента онкологии имени Н. Н. Блохина. E-mail: grig-elen11@mail.ru.

ЕЛЕНА СЕРГЕЕВНА МУТНЫХ - к.б.г., научный сотрудник института общей генетики имени Н.И. Вавилова, Российского экономического университета имени Г.В. Плеханова. E-mail: ledera@yandex.ru.

АЛЕКСЕЙ БОРИСОВИЧ ШЕВЕЛЕВ - Ә.б.н., главный научный сотрудник института общей генетики имени Н. И. Вавилова, Российскийого экономического университета им. Г. В. Плеханова. E-mail: shevel_a@ hotmail.com.

105122, Москва, Сиреневый бульвар, д. 4. Российский государственный университет физической культурь, спорта, молодежи и туризма, Министерство спорта Российской Федерации.

107014, Москва, ул. Барболина, 1Б, стр.1. Общество с ограниченной ответственностью «Глория».

109472, г. Москва, ул. Академика Скрябина, д. 23. Московская государственная академия ветеринарной медицины и биотехнологии- МВА имени К.И. Скрябина.

119334, Москва, ул. Косыгина, д. 4. Институт биохимической физики имени Н.М. Эмануэля РАН.

108819, поселение Московский, посёлок Института полиомиелита, домовладение 8, стр. 1, Москва. Федеральный научный центр исследований и разработки иммунологических препаратов имени М.П. Чумакова РАН. 
119991, Москва, ул. Трубецүкая, д. 8, стр. 2. Первый Московский государственный медииинский университет имени И.М. Сеченова (Сеченовский Университет).

115478, г. Москва, Каширское шоссе 23. Нацчинальный медицинский исследовательский иентр онкологии имени Н. Н. Блохина.

119991, ГСП-1 Москва, ул. Губкина, д. 3. Институт общей генетики имени Н. И. Вавилова.

117997, г. Москва, Стремянный пер., 36. Российский экономический университет имени Г. В. Плеханова.

Потребности диагностики заболеваний печени и билиарной системы требуют разработки простого неинвазивного теста с высокой чувствительностью и специфичностью. Соединения, меченные изотопом углерода, уже имеют широкое применение для диагностики различных заболеваний методами дыхательных тестов, безопасны и способны достоверно выявлять метаболические нарушения или дефицит спеиифических ферментов в органах. В рамках работы разработан способ получения линолевой кислоты, меченной углеродом-13 и углеродом-14, по степени очистки пригодной для проведения дыхательных тестов в целях диагностики заболеваний гепатобилиарной системь.

Ключевые слова: реактив Гриньяра, дыхательный тест, линолевая кислота, углерод-13, углерод-14, гепатобилиарная система, заболевания печени.

\title{
LABELING OF LINOLEIC ACID WITH CARBON-14 AND CARBON-13 TO CONDUCT DIAGNOSTIC RESPIRATORY TESTS OF DISEASES OF THE HEPATOBILIARY SYSTEM
}

\author{
Y.Y. Tynio ${ }^{1,2}$, G.V. Morozova ${ }^{3}$, Y. K. Biryukova ${ }^{4,5}$, D.A. Sivokhin ${ }^{6}$, A. V. Belyakova ${ }^{4,5}$, \\ N. V. Pozdniakova ${ }^{7}$, E. Y. Grigorieva ${ }^{7}$, E. S. Mutnykh ${ }^{8,9}$, A. B. Shevelev ${ }^{8,9}$
}

${ }^{1}$ Russian State University of Physical Education, Sport, Youth and Tourism (SCOLIPE), Ministry of Sport of the Russian Federation, 105122, Sirenevy Boulevard, 4, Moscow, Russian Federation.

${ }^{2}$ The limited liability company, Gloria LLC, st. Barbolina, 1, Moscow Region, Russian Federation.

${ }^{3}$ Moscow state Academy of Veterinary Medicine and Biotechnology - MVA by K.I. Skryabin, 119334, st. Akademika Skryabina, 23, Moscow, Russian Federation.

${ }^{4}$ Emanuel Institute of Biochemical Physics, 119334, Kosygina, 4, Moscow, Russian Federation.

${ }^{5}$ Chumakov Federal Scientific Center for Research and Development of Immune and Biological Products, Russian Academy of Sciences, 108819, Moskovsky settlement, village of the Institute of Poliomyelitis, household 8, p. 1, Moscow, Russian Federation.

${ }^{6}$ N.N. Blokhin National Medical Research Center of Oncology of the Ministry of Health of the Russian Federation, 115478, Kashirskoye Shosse 24, Moscow, Russian Federation.

${ }^{7}$ I.M. Sechenov First Moscow State Medical University (Sechenov University), 119991, 8-2 Trubetskaya str., Moscow, Russian Federation.

${ }^{8}$ General Genetics Institute named after N.I. Vavilov, 119991 ul. Gubkina, 3, Moscow, Russian Federation.

${ }^{9}$ Plekhanov Russian University of Economics, 117997, Stremyanny Lane, 36, Moscow, Russian Federation. 
Development of diagnosis of liver and biliary system diseases requires a simple non-invasive test with high sensitivity and specificity. Compounds labeled with carbon isotope are already widely used for the diagnosis of various diseases with respiratory tests. These are safe and reliable methods for detecting metabolic disorders or deficiency of specific enzymes in the organs. The present work describes a method for producing linoleic acid labeled with carbon-13 and carbon-14. Purity of the obtained products is suitable for respiratory tests for diagnosing diseases of the hepatobiliary system.

Keywords: Grignard reagent, respiratory test, linoleic acid, carbon-13, carbon-14, hepatobiliary system, liver diseases.

\section{Введение}

Численность наблюдаемых пациентов с хроническими заболеваниями печени, приводящими к циррозу (вирусные гепатиты В и С, алкогольные и токсические гепатиты, первичный склерозирующий холангит и др.), непрерывно растет [1].

Биопсия печени остается золотым стандартом оценки состояния органа. Однако инвазивность процедуры и связанные с этим риски осложнений для пациента не позволяют использовать этот метод в качестве рутинного [2]. Внедрение в практику методов неинвазивной диагностики, обладающих высокой достоверностью, простотой выполнения и безопасностью, как для самого пациента, так и обслуживающего персонала [3], позволит оценивать эффективность лечения в динамике, наличие функциональных резервов печени $[2,4]$. Этим функциональные тесты выгодно отличаются от эластографии или расчета лабораторных индексов APRI [5] или FORNS [6].

Диагностика на основе дыхательных тестов строится на способности различных органов и систем метаболизировать ${ }^{13} \mathrm{C}$ - и ${ }^{14} \mathrm{C}$-препараты с образованием ${ }^{13} \mathrm{CO}_{2}[7]$ или ${ }^{14} \mathrm{CO}_{2}[8]$, которые распределяются кровеносной системой по всем органам и тканям, и, выделяясь через лёгкие, могут быть достоверно обнаружены в выдыхаемом воздухе пациента с помощью масс-спектрометрии. Таким образом, появляется возможность постановки диагноза на основе анализа фармакокинетических показателей - изменения концентрации ${ }^{14} \mathrm{CO}_{2}$ в выдыхаемом воздухе во времени, имея информацию о путях и скоростях метаболических превращений препарата [9].

Уже разработаны и внедрены в практику дыхательные тесты для оценки функционального состояния печени на основе оценки скорости метаболизации ${ }^{13} \mathrm{C}$-Метацетина [1012], ${ }^{13} \mathrm{C}$-Галактозы и ${ }^{13} \mathrm{C}$-Аминофеназона [13] (оценивается активность цитохрома $\mathrm{P} 450),{ }^{13} \mathrm{C}$-фенилаланина [14], $[15],{ }^{13} \mathrm{C}$-кофеина $[16,17],{ }^{13} \mathrm{C} 3-$ триоктаноина (тройного эфира глицерина и ${ }^{13} \mathrm{C}$-каприловой кислоты) для обнаружения дефицита ферментов поджелудочной железы [7, 18].

Одним из наиболее перспективных направлений в ядерной медицине является использование дыхательных тестов на основе различных фармацевтических препаратов с использованием меченых жирных кислот, в частности линолевой. Это соединение играет существенную роль в энергетическом обмене клеток высших организмов и является строительными блоками для липидов нескольких классов, таких как нейтральные жиры, фосфоглицериды и эфиры холестерина [19].

Линолевая кислота является длиноцепочечным нерастворимым в воде соединением. В организме под действием желчи, выделяемой из желчного пузыря в тонком кишечнике, происходит гидролиз жирной кислоты с образованием смешанных мицелл. В случае нарушения работы гепатобилиарной системы, приводящего к нехватке желчных солей в желчи, происходит замедление всасывания меченых жирных кислот, что может быть обнаружено по изотопному составу выделяющегося углекислого газа [19].

Способы химического синтеза ${ }^{13} \mathrm{C}$ и ${ }^{14} \mathrm{C}$-производных наиболее распространённых в пищевых продуктах ненасыщенных жирных кислот: линолевой и линоленовой из наиболее доступного сырья - изотопно меченного $\mathrm{CO}_{2}$ в литературе не описаны. Биологические способы с применением водорослей и грибов имеют низкий радиохимический выход, не превышающий 60 \% [20]. Остальная часть изотопа выбрасывается в виде отходов, что с учётом большой длительности распада углерода-14 приводит к высокой экологической опасности схемы синтеза. Кроме того, недостатками известного из уровня техники биологического способа с точки зрения применимости ${ }^{13} \mathrm{C}-$ и ${ }^{14} \mathrm{C}$-жирных кислот в дыхательных тестах является распределение меченых атомов по всей длине углеродной цепи ацила. Между тем, для достижения высокой чувствительности, воспроизводимости и безопасности дыхательных тестов оптимальным является использование препаратов жирных кислот, имею- 
щих 100 \% меченного атома в позиции 1 (карбоксильная группа).

В настоящей работе мы представляем способ мечения линолевой кислоты углеродом-13 и углеродом-14 по положению 1 ацила (альфа), с использованием $\mathrm{CO}_{2}$ в качестве источника аномального изотопа для последующего использования в диагностике гепатобилиарной системы.

\section{Методика эксперимента}

\section{Оборудование}

Чистоту полученных промежуточных и конечных продуктов контролировали тонкослойной хроматографией на силикагеле на пластинкаx Kieselgel 60 F254 (Merck, Германия) и sorbfil ПТСХ-АФ-В-УФ, в системе этилацетат : гексан (1:1), структуру целевого продукта определяли спектроскопией ядерного магнитного резонанса на приборах моделей AM-300 (Bruker, Германия, 300 МГц) и DRX-500 (Bruker, Германия, 500 МГц), для определения удельной активности меченых атомов углерода использовали жидкостный сцинтилляционный счетчик DPM 7001 (НТЦ Радэк, Россия), оснащенный двумя фотоэлектронными умножителями, для определения активности смесей микрокалориметр Кальве Setaram C80 (Франция), $\mathrm{pH}$ растворов определяли потенциометрическим методом - $\mathrm{pH}$-метр модели Sartorius PB-11 (Германия).

\section{Материалье}

1-бром-8,11-гептадекандиен $\quad \mathrm{CH}_{3}\left(\mathrm{CH}_{2}\right)_{3}$ $\left(\mathrm{CH}_{2} \mathrm{CH}=\mathrm{CH}\right)_{2}\left(\mathrm{CH}_{2}\right)_{7} \mathrm{Br}$ AppliChem (США) со следующими характеристиками:

Физические свойства:

Молярная масса: 315,332 г/моль

Термические свойства:

Т. плав.: $5^{\circ} \mathrm{C}$

Т. кип.: $229^{\circ} \mathrm{C}$

Химические свойства:

Растворимость в воде: $1,5 \cdot 10^{-4} \mathrm{M}$ при рН 7,5

Источник стабильного изотопа углерода: безводный карбонат бария ${ }^{13} \mathrm{C}$ производства ООО «Ростхим», г. Москва со следующими характеристиками:

Изотопная чистота - 99,9 \%,

Молекулярная масса - 98,3359 г/моль,

Температура плавления $-3550{ }^{\circ} \mathrm{C}$.

Источник радиоактивного изотопа углерода: безводный карбонат бария ${ }^{14} \mathrm{C}$ производства $\mathrm{AO}$
«ИНСТИТУТ РЕАКТОРНЫХ МАТЕРИАЛОВ», $(\mathrm{AO}$ «ИРМ») г. Заречный Свердловской обл. со следующими характеристиками:

Изотопная чистота - 99,5 \%,

Молярная масса - 99,3359 г/моль

Температура плавления $-3550{ }^{\circ} \mathrm{C}$

Удельная радиоактивность - 2,961 мКи/г.

Использовали осушенные аргон и азот квалификации «высокая чистота» производства М-газ (Москва).

\section{Результаты и их обсуждение}

Получение линолевой кислоты меченой углеродом-13 и углеродом-14 в положении 1 (альфа) проводили в две стадии:

(1) получение реактива Гриньяра;

(2) карбоксилирование реактива Гриньяра двуокисью углерода-13 и углерода-14.

\section{1. Получение реактива Гриньяра}

Собирали установку из трёхгорлой колбы на 250 мл, в боковые горловины колбы вставляли хорошо действующий обратный холодильник с хлоркальциевой трубкой и капельную воронку с трубкой, уравнивающей давление во время прикапывания эфирного раствора. В центральное отверстие через масляный затвор вводили мешалку с электрическим приводом. В колбу помещали 3,0 г магниевой стружки и кристаллик йода. Всю установку продували током аргона марки ОСЧ в течение 20 минут. Через капельную воронку в колбу вводили 160 мл абсолютного эфира, включали мешалку и при слабом токе аргона прибавляли 315,332 г (12 ммоль) 1-бром-8,11гептадекандиена в виде раствора в диэтиловом эфире объемом 80 мл. Для начала реакции колбу нагревали на водяной бане до кипения эфира. После начала реакции водяную баню выключали и процесс перемешивания продолжали до полного растворения магния.

\section{2. Карбоксилирование реактива Гриньяра двуокисью углерода-13 и углерода-14}

Установка для получения меченых кислот карбоксилированием реактивом Гриньяра представляла собой высоковакуумную гребенку, снабженную шлифами для присоединения реакционной колбы, источника двуокиси углерода и ртутного манометра, а также трубками для входа и выхода азота. Коническая трёхгорлая реакционная колба была изготовлена с таким расчётом, чтобы её можно 
было замораживать, и снабжена магнитной мешалкой, позволяющей работать в вакууме при охлаждении.

Источник двуокиси углерода-13 и углерода-14 представлял собой круглодонную колбу, содержащую 5,4 ммоль изотопно меченного карбоната бария: для изотопа ${ }^{13} \mathrm{C}$ - навеска массой 0,531 г, для изотопа ${ }^{14} \mathrm{C}-0,536$ г. Колбу соединяли с заполненной концентрированной серной кислотой капельной воронкой, снабженной приспособлением для выравнивания давления. Эту часть установки соединяли с вакуумной гребенкой через трубку, наполненную осушителем.

Для проведения реакции установку откачивали с помощью масляного насоса до давления $10^{-4}$ мм и заполняли сухим азотом. Затем при помощи предварительно промытой и заполненной азотом пипетки с поршневой подачей быстро вводили в реакционную колбу раствор реактива Гриньяра, полученный из 6 ммоль 1-бром-8,11гептадекандиена. Свободный боковой отвод реакционной колбы закрывали пробкой, колбу охлаждали жидким азотом и откачали систему до давления $10^{-4}$ мм. После этого давали содержимому реакционной колбы оттаять, нагревая его смесью сухого льда к и ацетона до $20^{\circ} \mathrm{C}$, снова замораживали жидким азотом и опять откачали систему для удаления выделившегося азота.

Карбоксилирование реактива Гриньяра проводили при температуре $20{ }^{\circ} \mathrm{C}$, постоянно перемешивая содержимое колбы. Для запуска выделения изотопно меченного $\mathrm{CO}_{2}$ к карбонату бария из капельной воронки медленно прибавляли концентрированную серную кислоту, при этом следили за тем, чтобы давление в приборе не превышало 500 мм рт.ст. Для полного выделения меченного $\mathrm{CO}_{2}$ в конце реакции осторожно нагревали реакционную колбу с карбонатом бария до окончательного его растворения. После полного истощения реактива Гриньяра давление $\mathrm{CO}_{2}$ в приборе согласно показаниям манометра, переставало снижаться. По этому показателю как в случае ${ }^{13} \mathrm{CO}_{2}$, так и в случае ${ }^{14} \mathrm{CO}_{2}$ реакция полностью завершилась в течение 15 минут.

Затем реакционную колбу с реактивом Гриньяра охлаждали жидким азотом для того, чтобы в неё перешёл весь оставшийся в системе меченный $\mathrm{CO}_{2}$, закрыли кран, соединяющий прибор с источником меченного $\mathrm{CO}_{2}$, и для полного поглощения меченного $\mathrm{CO}_{2}$ реакционную массу перемешивали в течение 15 мин при температуре $-20^{\circ} \mathrm{C}$. После этого установку заполнили азотом и соединили с атмосферой. Полученный комплекс разлагали разбавленной соляной кислотой. Подкисленную смесь экстрагировали эфиром. Эфирный экстракт обработали $100 \mathrm{MM} \mathrm{NaOH}$ и подкислили полученный щелочной раствор до $\mathrm{pH}$ 7,0. Выделившуюся кислоту отфильтровали. Осадок собрали, промыли водой и перекристаллизовали из ацетонитрила при $20^{\circ} \mathrm{C}\left(t_{\text {замерз }}\right.$ линолевой кислоты считали равной $\left.11^{\circ} \mathrm{C}\right)$.

Масса полученной ${ }^{13} \mathrm{C}$-линолевой кислоты составила 1459 мг (5,184 ммоль). Итоговый химический выход реакции по 1-бром-8,11-гептадекандиену со-
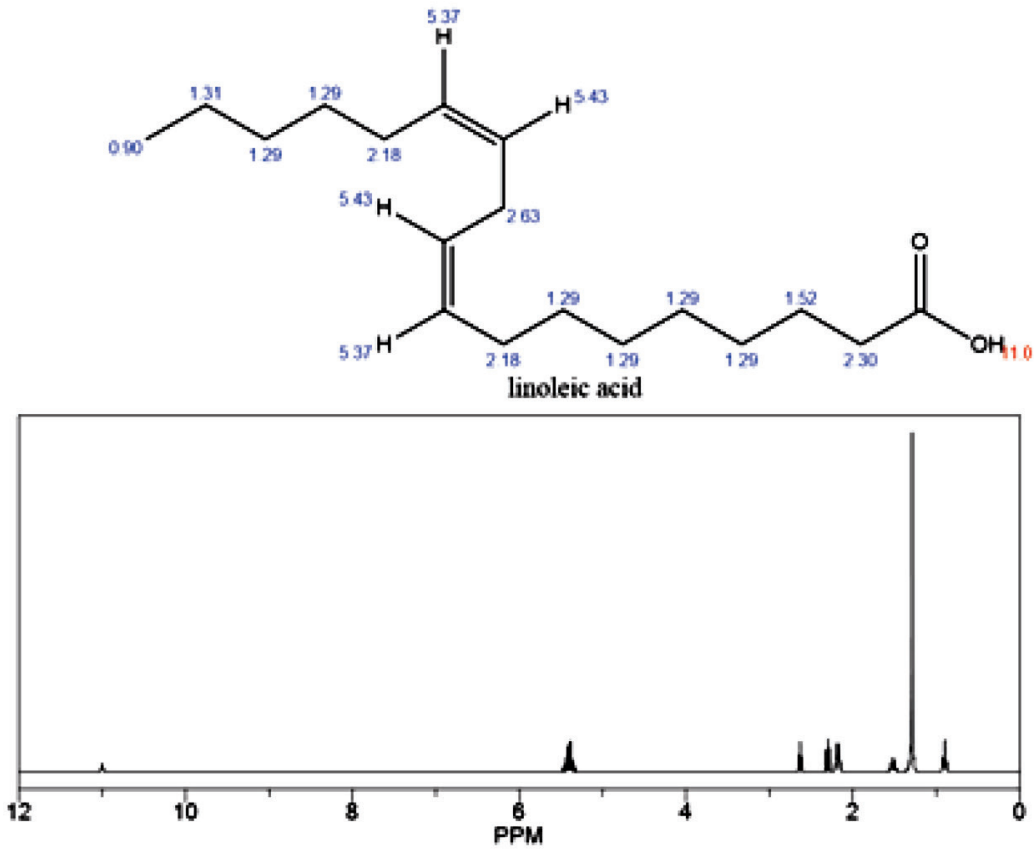

Рис. Спектр ${ }^{1}$ Н-ЯМР ${ }^{14}$ С-линолевой кислоты 
ставил $86,4 \%$, по ${ }^{13} \mathrm{CO}_{2}-96,0 \%$. Температура замерзания продукта составила $11,0{ }^{\circ} \mathrm{C}$.

Мacca полученной ${ }^{14} \mathrm{C}$-линолевой кислоты составила 1480 мг (5,243 ммоль). Итоговый химический выход реакции по 1-бром-8,11гептадекандиену составил 87,39 \%, по ${ }^{13} \mathrm{CO}_{2}-$ $97,1 \%$. Удельную активность ${ }^{14} \mathrm{C}$-линолевой кислоты определяли на сцинтилляционном спектрометре: она составила $1 \pm 0,02$ мКи/г. Таким образом, общий радиохимический выход составил $96,0 \%$. Препарат имел температуру замерзания $10,7^{\circ} \mathrm{C}$.

Анализ полученных образцов ${ }^{13} \mathrm{C}$ и ${ }^{14} \mathrm{C}$-линолевых кислот с помощью высокоэффективной хроматографии позволил обнаружить примеси кетонов и спиртов, которые в сумме не превышали $1,8 \%$ сухой массы готового продукта.

Спектр ЯМР ${ }^{14} \mathrm{C}$-линолевой кислоты по ${ }^{1} \mathrm{H}$ показал полное соответствие структуры синтезированного вещества линолевой кислоте (Рисунок).

\section{Выводы}

В рамках работы теоретически разработан и апробирован новый высокоэффективный способ получения линолевой кислоты, меченной изотопами углерода-13 и углерода-14. Вещества предназначены для проведения дыхательных тестов с массспектрометрической или радиологической детекцией меченного углекислого газа в выдыхаемом воздухе в целях диагностики заболеваний печени. Значимый результат работы состоит в ускорении процесса получения целевых продуктов, сокращении потерь меченного углекислого газа, в повышении его суммарного химического и радиационного выхода по сравнению с прототипом. Существенным результатом является также исключение распределения изотопно-меченных атомов по всей длине углеродной цепи ацила: при использовании разработанного метода включение происходит только в положении 1.

Упрощение и удешевление процесса получения целевых продуктов обеспечено уменьшением длительности реакции за счёт подбора оптимальных соотношений реагентов и использования теста на окончание реакции карбоксилирования реактива Гриньяра с помощью измерения давления углекислого газа в системе. Способ обеспечивает существенное повышение радиационного и химического выхода продукта по источнику изотопа по сравнению с известными способами $[7,12$, 20]. Включение меченного изотопа в целевой продукт приближается к количественному, в результате практически полностью исключается выброс радиоактивных отходов во внешнюю среду. С учётом затратности и сложности утилизации радиоак- тивных отходов с длительным периодом полураспада это играет существенную роль с точки зрения экономической эффективности способа.

Полученные в ходе работы образцы ${ }^{13} \mathrm{C}$-линолевой и ${ }^{14} \mathrm{C}$-линолевой кислот по своей чистоте и количеству пригодны для проведения доклинических испытаний острой, субхронической, хронической и других типов токсичности в соответствии с требованиями «Руководства по проведению доклинических исследований лекарственных средств» под ред. А.Н. Миронова и соавт. (2012 г). После подтверждения безопасности, соединения, изготавливаемые предлагаемым способом, могут быть рекомендованы для испытаний в клинических условиях в качестве диагностических дыхательных тестов в целях диагностики заболеваний гепатобилиарной системы.

Работа выполнена в рамках тематики Государственного Задания №0112-2019-0001 «Геномные исследования и генетический полиморфизм клетки, организма и популяиии» (руководитель Н.К. Янковский).

\section{Литература}

1. Liou I.W. Med. Clin. North Am., 2014. V. 98. N.1. P. 119-152. DOI:10.1016/j.mcna.2013.09.006

2. Joanna M., Jonderko K., Kasicka-Jonderko A., Buschhaus M.. Prz. Gastroenterol., 2015. V. 10. N. 1. P. 1-6. DOI:10.5114/pg.2014.47501.

3. Modak A.S. J. Breath Res. 2007. V. 1. N.1. DOI:10.1088/1752-7155/1/1/014003.

4. Mahadeva Sanjiv, Hamizah Razlan, Nurhayaty Muhamad Marzuki, Mei Ling Sharon Tai, Azhar Shah Shamsul, and Tze Zen Ong. Gastroenterol. Res. Pract. 2011. V. 2011. P. 10-12. DOI: $10.1155 / 2011 / 235796$.

5. Forns Xavier, Sergi Ampurdanès, Josep M. Llovet, John Aponte, Llorenç Quintó, Eva Martínez-Bauer, Miquel Bruguera, Jose Maria Sánchez-Tapias, and Juan Rodés. Hepatology. 2002. V. 36. N.4I. P. 986-992. DOI:10.1053/jhep.2002.36128.

6. Wai Chun Tao, Joel K. Greenson, Robert J. Fontana, John D. Kalbfleisch, Jorge A. Marrero, Hari S. Conjeevaram, and Anna S. Hepatology. 2003. V. 38. N. 2. P. 518-526. DOI: 10.1053/jhep.2003.50346.

7. Эльман A.P. J. Sci. Artic. "Health Educ. Millenn. 2013. P. 122-139.

8. Balãn Helena, Carol A. Gold, Howard J. Dworkin, Vince A. Mccormick, John E. Freitas, William Beaumont, Hospital Royal, St Joseph, Mercy Hospital, and Ann Arbor. J. Nucl. Med. 1998. V. 39. N. 11. P. 2012 2014

9. Grattagliano Ignazio, Bernhard H. Lauterburg, Giuseppe Palasciano, and Piero Portincasa. Eur. J. Clin. Invest. 2010. V. 40. N.9. P. 843-850. DOI: 10.1111/j.1365-2362.2010.02331.x. 
10. Gorowska-Kowolik K., Chobot A., and Kwiecien J.. Gastroenterol. Res. Pract. 2017. V. 2017. P. 1-5.

11. Moran Segundo, Aline Mina, Ximena Duque, Nayeli Ortiz-Olvera, Gustavo Rodriguez-Leal, Jose Alfredo Sierra-Ramírez, Roberto Medina-Santillán, Robertino M. Mera, and Misael Uribe. J. Breath Res. 2017. V. 11. N. 3. DOI: 10.1088/1752-7163/aa7b99.

12. Эльман A.P. et al. Рос. хим. ж. (Ж. Рос. хим. об-ва им. Д.И. Менделеева). 2013. Т. LVII. № 5.

13. Giannini Edoardo G., Alberto Fasoli, Paolo Borro, Federica Botta, Federica Malfatti, Alessandra Fumagalli, Emanuela Testa, Simone Polegato, Tiziana Cotellessa, Sara Milazzo, Domenico Risso, and Roberto Testa. Clin. Gastroenterol. Hepatol. 2005. V. 3. N. 3. P. 279-285. DOI: 10.1016/S1542-3565(04)00720-7.

14. Moran Segundo, Irazu Gallardo-Wong, Gustavo Rodriguez-Leal, Paulina McCollough, Jorge Mendez, Beatriz Castañeda, Pilar Milke, Janet Jacobo, and Margarita Dehesa. Isotopes Environ. Health Stud. 2009. V. 45. N. 3. P. 192-197. DOI: 10.1080/10256010903083995.
15. Zhang Gan Sheng, Zhi Jun Bao, Jian Zou, Shu Ming Yin, Yi Qin Huang, Hai Huang, and De Kai Qiu. BMC Geriatr. 2010. V. 10. DOI: 10.1186/1471-2318-10-23.

16. Schmilovitz-Weiss H., Niv Y., Pappo O., Halpern M., Sulkes J., Braun M., Barak N., Rotman Y., Cohen M., Waked A., and Tur-Kaspa R. J. Clin. Gastroenterol. 2008. V. 42. N.4. P. 408-412. DOI:10.1097/ MCG.0b013e318046ea65.

17. Park Gordon J. H., Elke Wiseman, Jacob George, Peter H. Katelaris, Francis Seow, Caroline Fung, and Meng C. Ngu. J. Gastroenterol. Hepatol.2011. V. 26. N.9. P. 1411-1416. DOI: 10.1111/j.1440-1746.2011.06760.x.

18. Braden B.. Pancreas. 2010. V. 39. N. 7. P. 955-959. DOI: 10.1097/MPA.0b013e3181dbf330.

19. Т Титов В.Н. Научно-практический журнал «Клиниколабораторный консилиум». 2014. V. 2. N. 49.

20. Kawashima Hiroshi, Kengo Akimoto, Tsuyoshi Fujita, Hideo Naoki, Kyoko Konishi, and Sakayu Shimizu. Analytical Biochemistry. 1995. V. 229. N.2. P. 317-322. DOI:10.1006/abio.1995.1419. 